\title{
Uremic Leontiasis Ossea
}

\author{
Jien Shim and *Run Yu
}

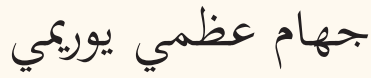

جين شيم و رن يو
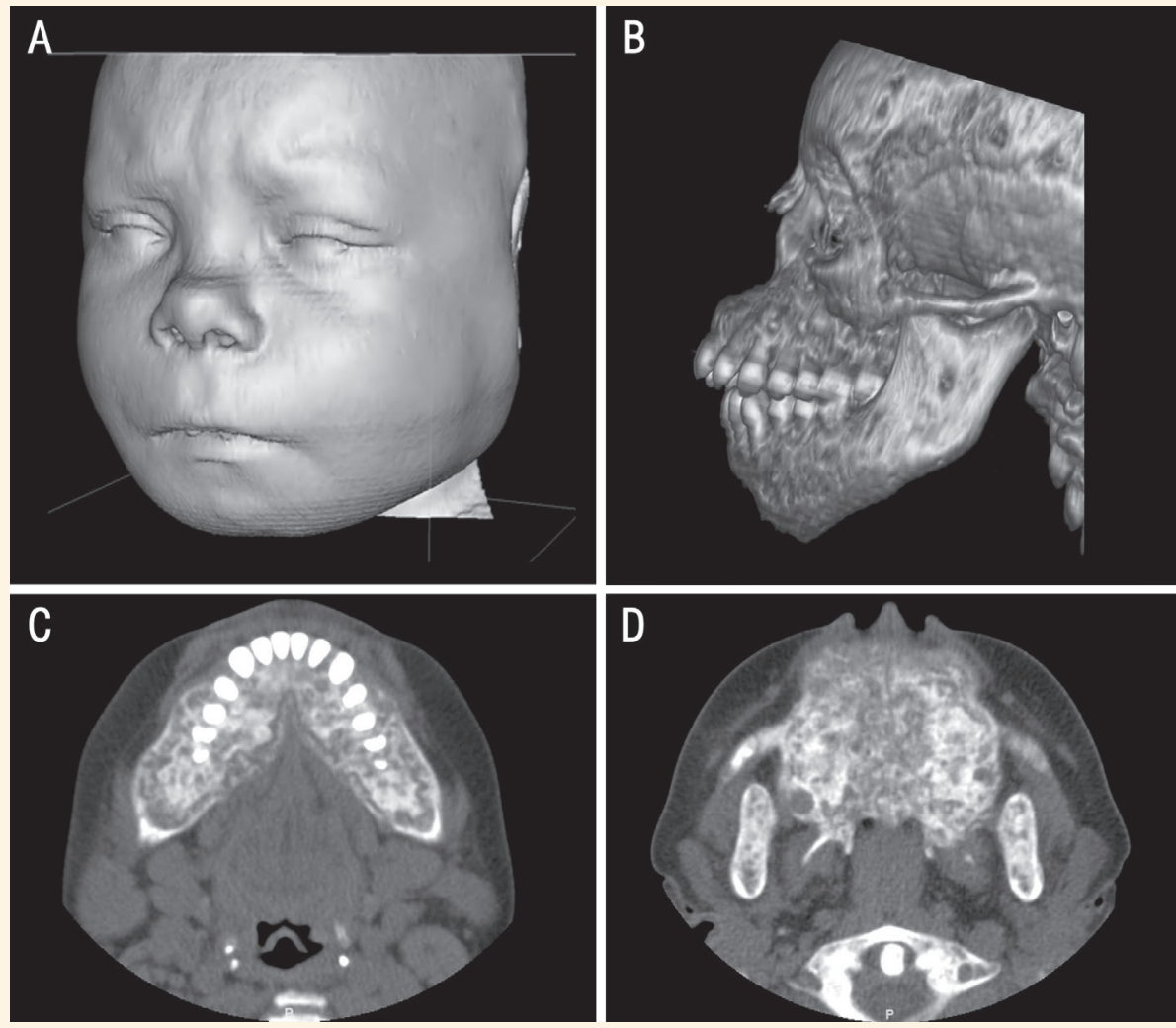

Figure 1: Three-dimensional reconstructions of the (A) facial features and (B) bones of a 23-year-old female with uremic leontiasis ossea based on non-contrast sinus computed tomography of the (C) mandible and (D) maxilla.

A 23-YEAR-OLD FEMALE PATIENT PRESENTED to the Ronald Reagan University of California California, in 2016 with a two-month history of progressive swelling and pain of the upper and lower jaws and palate, drooling, lisping and difficulty chewing and swallowing. She had undergone a bilateral nephrectomy due to a bilateral Wilms' tumour 22 years prior at 14 months of age. She then received haemodialysis until she was six years old, at which time she received a kidney transplant. However, the transplanted kidney failed due to medication noncompliance and she subsequently resumed haemodialysis at the age of 16 years. She had secondary hyperparathyroidism and was noncompliant with medications to control the disorder. She also had congestive heart failure and cryptogenic organising pneumonia requiring home oxygen therapy. She had no family history of hyperparathyroidism.

A physical examination revealed maxillary and mandibular swelling, tenderness and wide interdental spacing. Before haemodialysis, the patient's parathyroid hormone level was $>1,700 \mathrm{pg} / \mathrm{mL}$ (normal range: $11-51 \mathrm{pg} / \mathrm{mL}$ ), total calcium level was $10.3 \mathrm{mg} / \mathrm{dL}$ (normal range: $8.6-10.3 \mathrm{mg} / \mathrm{dL}$ ), ionised calcium level was $1.09 \mathrm{mmol} / \mathrm{L}$ (normal range: $1.09-1.29 \mathrm{mmol} / \mathrm{L}$ ), phosphorus level was $7.3 \mathrm{mg} / \mathrm{dL}$ (normal range: 
2.3-4.4 mg/dL), 25-hydroxyvitamin D level was $16 \mathrm{ng} / \mathrm{mL}$ (normal range: $20-50 \mathrm{ng} / \mathrm{mL}$ ) and serum alkaline phosphatase level was 1,610 U/L (normal range: $37-113 \mathrm{U} / \mathrm{L}$ ).

Three-dimensional reconstructions and axial non-contrast sinus computed tomography (CT) scans showed deformities of the mouth and nose, gross expansion of the mandible, maxilla and calvaria, overbite and overjet, diffuse mixed sclerotic and lytic changes to all visualised osseous structures and regions of focal lytic expansion in the mandible and maxilla [Figure 1]. Subsequently, the patient was diagnosed with uremic leontiasis ossea (ULO). Due to her significant cardiopulmonary comorbidities and high perioperative risk, a parathyroidectomy was not possible. The patient was advised to resume medical therapy with cinacalcet, calcitriol and sevelamer. However, one month later, the patient was found to be only intermittently compliant with these medications and did not exhibit significant clinical improvement.

\section{Comment}

Chronic kidney disease-associated mineral and bone disorders (CKD-MBDs), previously termed renal osteodystrophy, include hormonal abnormalities such as secondary hyperparathyroidism, deranged bone turnover and mineralisation and extraskeletal calcification. ${ }^{1}$ Also known as maxillary hyperplasia and hyperostosis cranialis, ULO is the rarest and most severe form of CKD-MBDs; it usually occurs in young adults with longstanding chronic renal failure and poorly controlled secondary or tertiary hyperparathyroidism, as in the current case. ${ }^{2-4}$ While the specific pathogenesis of ULO is unknown, deranged bone turnover and mineralisation caused by poorly controlled secondary hyperparathyroidism is likely a key feature. ${ }^{2}$
The term ULO is derived from the appearance of the facial deformity due to bony overgrowth around the oral cavity which resembles the face of a lion. Radiographically, ULO manifests as hypertrophy and hyperostosis of the facial bones and calvaria, especially the maxilla and mandible, and diffuse mixed sclerotic and lytic changes best illustrated by non-contrast $\mathrm{CT} .^{2-5}$ The reason as to why the facial bones and calvaria are selectively affected in ULO cases is not clear. In the current case, the affected patient had all of the typical clinical, laboratory and radiographical features of ULO.

If left untreated, patients with ULO may develop severe disfigurement, dysphagia, speech impairment, respiratory distress and blindness. ${ }^{2-4}$ The management of ULO cases should focus on controlling secondary or tertiary hyperparathyroidism, either with medication or surgically with a parathyroidectomy. ${ }^{3}$ Unfortunately, surgical resection was not feasible in the current case and the patient did not adhere to prescribed medical therapy. As such, there was no evidence of clinical improvement at a one-month follow-up appointment.

\section{References}

1. Zangeneh F, Clarke BL, Hurley DL, Watts NB, Miller PD. Chronic kidney disease-mineral and bone disorders (CKDMBDs): What the endocrinologist needs to know. Endocr Pract 2014; 20:500-16. doi: 10.4158/EP12291.RA.

2. Lee VS, Webb MS Jr, Martinez S, McKay CP, Leight GS Jr. Uremic leontiasis ossea: "Bighead" disease in humans? Radiologic, clinical, and pathologic features. Radiology 1996; 199:233-40. doi: 10.1148/radiology.199.1.8633151.

3. Bakathir AA, Margasahayam MV, Al-Ismaily MI. Maxillary hyperplasia and hyperostosis cranialis: A rare manifestation of renal osteodystrophy in a patient with hyperparathyroidism secondary to chronic renal failure. Saudi Med J 2008; 29:1815-18.

4. Stoopler ET, Aloyouny A, Greenberg MS. Uremic leontiasis ossea. Am J Med Sci 2017; 354:527. doi: 10.1016/j.amjms.2017. 07.004 .

5. Abdel Razek AA. Computed tomography and magnetic resonance imaging of maxillofacial lesions in renal osteodystrophy. J Craniofac Surg 2014; 25:1354-7. doi: 10.1097/SCS.00 00000000000819 